\title{
The genetic and biological basis of feed efficiency in mid-lactation Holstein dairy cows
}

\author{
L. C. Hardie, ${ }^{* 1}$ M. J. VandeHaar,† R. J. Tempelman,† K. A. Weigel,‡ L. E. Armentano, $\ddagger$ G. R. Wiggans,§ \\ R. F. Veerkamp,\# Y. de Haas,\# M. P. Coffey,Il E. E. Connor,§ M. D. Hanigan,ף C. Staples, ${ }^{* *} Z$. Wang,†† \\ J. C. M. Dekkers, ${ }^{*}$ and D. M. Spurlock* \\ *Department of Animal Science, lowa State University, Ames 50011 \\ †Department of Animal Science, Michigan State University, East Lansing 48824 \\ ‡Department of Dairy Science, University of Wisconsin, Madison 53706 \\ §Animal Genomics and Improvement Laboratory, Agricultural Research Service, USDA, Beltsville, MD 20705 \\ \#Animal Breeding and Genomics Centre, Wageningen UR Livestock Research, $6700 \mathrm{AH}$, the Netherlands \\ IIScottish Agricultural College, Easter Bush, Midlothian, EH25 9RG, United Kingdom \\ IDepartment of Dairy Science, Virginia Tech, Blacksburg 24061 \\ ${ }_{* \star}$ Department of Animal Sciences, University of Florida, Gainesville 32611 \\ ††Department of Agricultural, Food, and Nutritional Science, University of Alberta, Edmonton, T6G 2P5 Canada
}

\begin{abstract}
The objective of this study was to identify genomic regions and candidate genes associated with feed efficiency in lactating Holstein cows. In total, 4,916 cows with actual or imputed genotypes for 60,671 single nucleotide polymorphisms having individual feed intake, milk yield, milk composition, and body weight records were used in this study. Cows were from research herds located in the United States, Canada, the Netherlands, and the United Kingdom. Feed efficiency, defined as residual feed intake (RFI), was calculated within location as the residual of the regression of dry matter intake (DMI) on milk energy (MilkE), metabolic body weight (MBW), change in body weight, and systematic effects. For RFI, DMI, MilkE, and MBW, bivariate analyses were performed considering each trait as a separate trait within parity group to estimate variance components and genetic correlations between them. Animal relationships were established using a genomic relationship matrix. Genome-wide association studies were performed separately by parity group for RFI, DMI, MilkE, and MBW using the Bayes B method with a prior assumption that $1 \%$ of single nucleotide polymorphisms have a nonzero effect. One-megabase windows with greatest percentage of the total genetic variation explained by the markers (TGVM) were identified, and adjacent windows with large proportion of the TGVM were combined and reanalyzed. Heritability estimates
\end{abstract}

Received January 16, 2017.

Accepted July 12, 2017.

${ }^{1}$ Corresponding author: lhardie@psu.edu for RFI were $0.14( \pm 0.03 ; \pm \mathrm{SE})$ in primiparous cows and $0.13( \pm 0.03)$ in multiparous cows. Genetic correlations between primiparous and multiparous cows were 0.76 for RFI, 0.78 for DMI, 0.92 for MBW, and 0.61 for MilkE. No single 1-Mb window explained a significant proportion of the TGVM for RFI; however, after combining windows, significance was met on Bos taurus autosome 27 in primiparous cows, and nearly reached on Bos taurus autosome 4 in multiparous cows. Among other genes, these regions contain $\beta-3$ adrenergic receptor and the physiological candidate gene, leptin, respectively. Between the 2 parity groups, 3 of the 10 windows with the largest effects on DMI neighbored windows affecting RFI, but were not in the top 10 regions for MilkE or MBW. This result suggests a genetic basis for feed intake that is unrelated to energy consumption required for milk production or expected maintenance as determined by MBW. In conclusion, feed efficiency measured as RFI is a polygenic trait exhibiting a dynamic genetic basis and genetic variation distinct from that underlying expected maintenance requirements and milk energy output.

Key words: genome-wide association study, residual feed intake, feed efficiency, dairy

\section{INTRODUCTION}

Improvement in feed efficiency in dairy cattle is important in that it results in reduced greenhouse gas emissions (Knapp et al., 2014), less land and resources needed for the production of feed (von Keyserlingk et al., 2013), and economic benefits through reduced inputs for equivalent output, as feed represents more than $50 \%$ of the total cost of producing milk (USDA- 
NASS, 2015). Over the past $100 \mathrm{yr}$, cows have become more feed efficient largely through increases in milk production, thereby diluting the proportion of feed used for maintenance (VandeHaar and St-Pierre, 2006). However, because this effect diminishes with each successive incremental in production relative to body size, continued gains via this route are diminishing (VandeHaar et al., 2016), warranting the exploration of the genetic basis of feed utilization in lactating dairy cattle for targeted selection.

Identifying genetically superior animals for feed efficiency is a difficult task that requires many animals with phenotypes to accurately predict an animal's genetic merit for feed efficiency. Thus, large collaborations between European, North American, and Australasian researchers have been established to pool feed intake data (Berry et al., 2014; de Haas et al., 2015; Tempelman et al., 2015). In one collaboration, nearly 5,000 cows were genotyped and phenotyped for feed intake and related traits (Tempelman et al., 2015; VandeHaar et al., 2016). Specifically, these cows have phenotypes for residual feed intake (RFI), which is defined as the actual intake minus the intake expected based on level of production and animal size (Koch et al., 1963). In mid-lactation dairy cows, RFI is often computed as the residual of the regression of intake on a form of ECM production, metabolic BW (MBW), and energy gained or lost in body tissues. Tempelman et al. (2015) estimated RFI to have a heritability of 0.15 to 0.18 in this population, suggesting a genetic basis to RFI.

Presently, a limited number of genome-wide association studies (GWAS) have been performed to identify QTL and, subsequently, candidate genes related to feed efficiency traits in dairy cattle. These studies have either used relatively small populations with limited power to detect QTL (Verbyla et al., 2010; Yao et al., 2013) or investigated the genetic architecture of feed efficiency in nonlactating heifers (Pryce et al., 2012) or only primiparous cows (Veerkamp et al., 2012; Tolkamp et al., 2014). However, biological mechanisms underlying variation in feed efficiency in growing animals may not be the same as that for mature lactating animals (Spurlock and VandeHaar, 2013).

The first goal of our study was to identify genomic regions associated with RFI in lactating Holstein cows and compare those regions to QTL influencing traits underlying RFI, including DMI, maintenance energy requirements, and milk energy output. The second goal was to identify potential candidate genes located within RFI QTL and known to function within physiological pathways relevant to feed efficiency. To that end, we used data from nearly 5,000 lactating Holstein cows to identify genomic regions and candidate genes associated with RFI and related traits. Differences in the genetic basis of RFI associated with parity were also explored.

\section{MATERIALS AND METHODS}

\section{Data Collection}

For detailed information on the collection of phenotypes used in this project, see Tempelman et al. (2015). For the current study, phenotypes meeting the criteria outlined below were available on 6,453 cows from research stations within the United States, Canada, the Netherlands, and the United Kingdom. Records were very heterogeneous, as described in Tempelman et al. (2015); however, for each cow, most of the research stations provided daily feed intake and milk production, a minimum of starting and ending BW for the recording period, and biweekly observations of milk fat, protein, and lactose percentages. Only measurements collected between 50 and 200 DIM were used because this is when the cow is at peak DMI and BW is relatively stable.

Individual measurements were edited and then combined to form one 28-d average phenotype each for DMI, milk energy (MilkE; determined as the sum of the energy in the fat, protein, and lactose in the milk; NRC, 2001), MBW $\left(\mathrm{BW}^{0.75}\right)$, and change in BW $(\Delta \mathrm{BW})$. Phenotypes for RFI were calculated similarly to Tempelman et al. (2015) within location as the residual of the regression of DMI on MilkE, MBW, and $\Delta \mathrm{BW}$ plus systematic effects:

$$
\begin{gathered}
D M I_{i j l m}=\text { parity }_{i}+\sum_{k=0}^{5} b_{i k} D I M_{i j l m}^{k}+\beta_{1} M i l k E_{i j l m}+\beta_{2} M B W_{i j l m}+ \\
\beta_{3} \Delta B W_{i j l m}+E_{j}+D_{l}\left(E_{j}\right)+T_{m}+R F I_{i j l m}
\end{gathered}
$$

where parity $_{i}$ is the fixed effect of parity (primiparous or multiparous), $\sum_{k=0}^{5} b_{i k} D I M_{i j l m}^{k}$ is the 5th-order Legendre polynomial regression of DMI on DIM with parityspecific regression coefficients $b_{i k}, \beta_{1}$ is the partial regression coefficient of DMI on MilkE, $\beta_{2}$ is the partial regression coefficient of DMI on MBW, $\beta_{3}$ is the partial regression coefficient of DMI on $\Delta \mathrm{BW}, E_{j}$ is the fixed effect of experiment, $D_{l}\left(E_{j}\right)$ is the random effect of diet within experiment, $T_{m}$ is the random effect of test date, and $R F I_{i j l m}$ is the random error term and the phenotype used for RFI in further analyses. Test date was defined as the middle date of the window during which the cow had data recorded.

Genotypes were determined using various commercially available SNP chips, with the number of genotypes per cow ranging from 3,000 to 777,000. All 
Table 1. Distribution of cow records with phenotype and genotype data by parity and location

\begin{tabular}{lccc}
\hline Item, no. & Primiparous & Multiparous & Total number of unique cows ${ }^{1}$ \\
\hline United States & 1,916 & 1,843 & 3,309 \\
Canada & 213 & 112 & 220 \\
The Netherlands & 581 & 372 & 937 \\
United Kingdom & 365 & 340 & 450 \\
Total & 3,075 & 2,667 & 4,916 \\
\hline
\end{tabular}

${ }^{1}$ Difference between sum of primiparous and multiparous records and total number of unique cows is the number of cows contributing to both primiparous and multiparous records.

genotype data were processed by the Animal Genomics and Improvement Laboratory (http://aipl.arsusda.gov; Wiggans et al., 2014). A final data set with genotypes for 60,671 SNP for each animal was generated using imputation methods employed through the software findhap (http://aipl.arsusda.gov/software/findhap/). If a SNP was not able to be called and no other animals shared the individual's haplotype to permit imputation, it was considered missing. In total, 4,916 cows had genotypes and phenotypes for all traits, and each cow had up to 1 primiparous and 1 multiparous record used (Table 1). Therefore, 3,075 primiparous records and 2,667 multiparous records were used, and, after imputation, these cows had 3.0 and $3.1 \%$ missing genotypes, respectively. Because a permanent environmental effect was not fitted, if a cow had multiple multiparous records the parity used was randomly chosen.

\section{Genetic Parameters}

Variance components, heritabilities, and genetic correlations for each trait (RFI, DMI, MilkE, and MBW) between first and second or greater parities were estimated using bivariate analyses in ASReml 4.0 (Gilmour et al., 2015). For each trait, the phenotype measured during first parity was considered as trait 1 and the phenotype measured in a second or greater parity was considered trait 2. Even though little to no culling based on feed efficiency was experienced in the herds providing data, by using bivariate analyses we accounted for any bias in variance component estimation that may have been due to culling. For DMI, MilkE, and MBW, within each trait, the following model was used:

$$
\begin{aligned}
y_{i j l m n o}= & \mu_{i}+\sum_{k=1}^{5} D I M_{i j l m n o}^{k}+L_{i j}+D_{m}\left[E_{l}\left(L_{j}\right)\right]_{i}+ \\
& T_{n}\left(L_{j}\right)_{i}+g_{i o}+\varepsilon_{i j l m n o},
\end{aligned}
$$

where parity-specific (primiparous or multiparous) fixed and random effects were denoted by subscript $i, y_{i j l m n o}$ is the observed DMI, MilkE, or MBW with overall mean $\mu_{i}, \sum_{k=1}^{5} D I M_{i j l m n o}^{k}$ is the 5th-order Legendre polynomial regression of $y$ on DIM, $L_{j}$ is the fixed class effect of location (12 levels), $D_{m}\left[E_{l}\left(L_{j}\right)\right]_{i}$ is the random effect of diet within experiment within location, $T_{n}\left(L_{j}\right)_{i}$ is the random effect of test date within location, $g_{i o}$ is the random genetic effect of animal, and $\varepsilon_{i j l m n o}$ is the random error. Random effects were assumed to follow multivariate normal distributions, with mean equal to zero and covariance matrix:

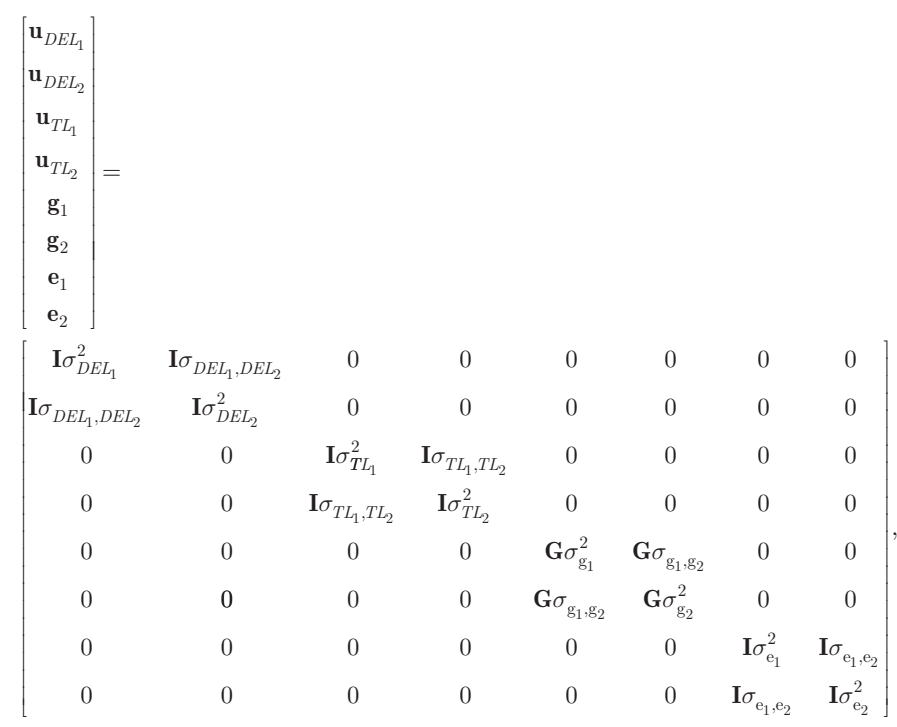

where the vectors $\mathbf{u}_{D E L i}$ contain solutions for the interaction of diet within experiment within location for parity group $i$, with subscripts 1 and 2 denoting primiparous and multiparous records, respectively; $\mathbf{u}_{T L i}$ denotes vectors of solutions for location-specific effects of test dates for parity group $i$; $\mathbf{g}$ denotes the solutions for the random animal polygenic effects for parity group $i$; and $\mathbf{e}$ denotes the vector of random residuals for parity group $i$. The identity matrix is denoted with $\mathbf{I} ; \mathbf{G}$ denotes the genomic relationship matrix that was constructed according to the first method of VanRaden (2008) using the 4,916 animals with phenotypes and genotypes; $\sigma_{D E L_{i}}^{2}$ denotes the variance component for 
the interaction of diet within experiment within location for parity group $i$ with subscripts 1 and 2 denoting primiparous and multiparous records, respectively; $\sigma_{D E L_{1}, D E L_{2}}$ denotes the covariance between primiparous and multiparous cows for the interaction of diet within experiment within location; $\sigma_{T L_{i}}^{2}$ denotes the variance component for location-specific effects of test dates for parity group $i$, with subscripts 1 and 2 denoting the covariance between parity groups for location-specific effects of test dates; $\sigma_{\mathrm{g}}^{2}$ denotes the animal polygenic variance for parity group $i$ with $\sigma_{\mathbf{g}_{1}, \mathbf{g}_{2}}$ denoting the polygenic covariance between parity groups; and $\sigma_{\mathbf{e}_{i}}^{2}$ denotes the residual variance component for parity group $i$, with $\sigma_{\mathbf{e}_{1}, \mathbf{e}_{2}}$ denoting the residual covariance between the 2 parity groups. Because systematic effects were accounted for during calculation of RFI, only the animal effect was considered in the bivariate analysis between RFI estimated in primiparous and multiparous cows.

\section{GWAS}

Genome-wide association studies were performed to identify QTL related to RFI, DMI, MBW, and MilkE using GenSel version 4.0 (Fernando and Garrick, 2009; Garrick and Fernando, 2013). Because the current version of GenSel does not accommodate random effects other than marker effects, adjusted phenotypes were calculated as the sum of the animal and residual terms from univariate analyses according to the models described above. Method Bayes B was used to identify QTL using the following model:

$$
y_{i}=\mu+\sum_{j=1}^{k} \delta_{j} m_{i j} \alpha_{j}+e_{i},
$$

where $y_{i}$ is the phenotype, $\mu$ is the overall mean, $\sum_{j=1}^{k} \delta_{j} m_{i j} \alpha_{j}$ is the genomic breeding value, modeled as the sum across $k$ SNP, with inclusion factor $\delta_{j}$ (coded 0 or 1 with prior probabilities $\pi$ and $1-\pi$, respectively, $\pi$ set equal to 0.99 ), genotype $m$ (coded as $0,1,2$, or average for missing genotypes), allele substitution effect $\alpha_{j}$ for SNP $j$, and random residual $e_{i}$. Method Bayes B assumes that the effect of each SNP follows an independent, normal distribution with null mean and unknown SNP-specific variance. Therefore, the variance of each SNP is allowed to differ. All nonmonomorphic SNP were used and missing genotypes were replaced with the average genotype for that SNP (Boddicker et al.,
2012). GenSel cannot accommodate missing values for SNP; thus, by replacing the missing genotype with the mean genotype for that SNP, that genotype does not contribute to the estimate of the SNP effect. Priors for genetic and residual variances used in the above model were estimated using method Bayes C, with all SNP included in the model $(\pi=0$; Habier et al., 2011). For this method, SNP effects are expected to follow a normal distribution with null mean and common variance $\sigma_{a}^{2}$ (Fernando and Garrick, 2013). For both Bayes B and Bayes C, Markov chain Monte Carlo sampling with a minimum of 120,000 iterations was used to estimate posterior means of SNP substitution effects, with the first 20,000 iterations discarded. Convergence was assessed through visual inspection of the samples of the genetic variance.

The SNP were binned into nonoverlapping $1-\mathrm{Mb}$ windows according to the UMD 3.1 map of the Bos taurus genome (http://bovinegenome.org/; GenBank accession: DAAA00000000.2), and the proportion of genetic variation explained by each window was estimated following Wolc et al. (2012). Under a pure polygenic model, it was assumed that each $1-\mathrm{Mb}$ window explained an equal amount of the total genetic variance. Thus, the bovine genome was divided into 2,676 1-Mb windows, such that the expected percent of the total genetic variation explained by the markers (TGVM) in each $1-\mathrm{Mb}$ window was $0.037 \%$. For each iteration, the TGVM within each window was calculated by multiplying the SNP effects by each individual's SNP genotypes, summing across all SNP in that window, and calculating the variance across all individuals (Wolc et al., 2012). The proportion of variance explained by the window was calculated by dividing the window variance by the variance across all markers in the genome. Windows with variances greater than expected $(0.037 \%)$ for greater than $80 \%$ of the iterations were considered the most probable in harboring a QTL and declared significant (Wolc et al., 2012). Additional windows of interest were defined as any nonsignificant window of the 10 windows explaining the greatest proportion of TGVM for each analysis.

Under the hypothesis that SNP located in adjacent windows explaining large proportions of the total genetic variance were doing so because of linkage disequilibrium with a single QTL, these windows were combined into an extended window to estimate the total amount of genetic variance explained by that QTL. Specifically, the decision to combine windows was made if 2 adjacent or nearly adjacent windows were among the 10 explaining the greatest proportion of TGVM for each analysis. Additionally, the window was extended beyond $2 \mathrm{Mb}$ so that it was continuous 
and to include any other adjacent windows in the $2 \%$ of windows explaining the greatest proportion of TGVM for each analysis. As with $1-\mathrm{Mb}$ windows, confidence that an extended window harbored a QTL was tested by considering whether or not it explained a greater than expected percent of the TGVM. To calculate the expected TGVM for these extended windows, the expected percentage of the TGVM for each 1-Mb window $(0.037 \%)$ was multiplied by the number of $1-\mathrm{Mb}$ windows that were combined. Estimates of the percentage of the TGVM of each extended window were generated using Markov chain Monte Carlo sampling with 120,000 iterations, with every 100th iteration of the last 100,000 iterations stored. As with $1-\mathrm{Mb}$ windows, a threshold of 0.80 was used such that if greater than $80 \%$ of the iterations generated a percentage of the TGVM greater than expected for the extended window, the region was defined as significant and harboring a QTL.

\section{Identification of Candidate Genes}

Positional candidate genes that may harbor mutations underlying the genetic variance in windows with the greatest percentage of the TGVM were explored using the NCBI genome database (http://www.ncbi.nlm .nih.gov/genome/) and BioMart (www.ensembl.org). Focus was on genes located in significant regions or 2 $\mathrm{Mb}$ up- and downstream of the significant $1-\mathrm{Mb}$ windows, as recommended based on simulation (Garrick and Fernando, 2013) or within the extended window. Prior evidence of QTL near or in significant 1-Mb extended windows or windows of interest was explored using Animal QTLdb (www.animalgenome.org/QTLdb/; $\mathrm{Hu}$ et al., 2016).

\section{RESULTS AND DISCUSSION}

Records from a total of 4,916 cows were used, and 826 of these cows contributed both primiparous and multiparous phenotypes (Table 1). On average, mul- tiparous cows had greater DMI, MBW, and MilkE compared with primiparous cows (Table 2). The range in RFI of multiparous cows was approximately twice as great as that of primiparous cows.

\section{Genetic Parameters}

Feed efficiency is a complex trait (an outcome) that is influenced by multiple underlying traits, including DMI, milk production, and maintenance energy requirements. Heritability estimates for DMI, MBW, and MilkE in primiparous and multiparous cows ranged from 0.20 to 0.51 (Table 3), which is within the range of estimates previously established for these traits (e.g., Veerkamp, 1998; Veerkamp et al., 2012). Our research also establishes a significant genetic component for RFI with heritability estimates, ranging from 0.13 to 0.18 based on the current genomic analyses (Table 3 ) and traditional pedigree (Tempelman et al., 2015). Identifying and understanding the function of biological pathways underlying this genetic regulation of RFI could aid in the development of genetic, management, or nutritional strategies to improve feed efficiency in dairy herds. However, a challenge in understanding this genetic architecture is that RFI appears to be a truly multigenic trait influenced by many genes, each having a relatively small effect (Verbyla et al., 2010; Pryce et al., 2012; Yao et al., 2013). Thus, it is important to minimize nongenetic factors that may compromise the ability to identify specific genomic regions of importance. In the current study, we analyzed data separately for primiparous and multiparous cows because of potential physiological differences between parities that could influence the RFI phenotype. Most notably, primiparous cows typically continue to grow in frame throughout their first lactation (Perotto et al., 1992), which may affect the utilization of energy in primiparous compared with multiparous cows. It is quite notable that the range of RFI phenotypes was greater for multiparous cows compared with primiparous cows in

Table 2. Means ( $\pm \mathrm{SD}$; with minimum, maximum in parentheses) for primiparous $(\mathrm{n}=3,075)$ and multiparous $(\mathrm{n}=2,667)$ cows for residual feed intake (RFI), DMI, metabolic BW (MBW), milk energy (MilkE), milk yield $(\mathrm{MY})$, percentage fat in milk, percentage protein in milk, change in BW $(\Delta \mathrm{BW})$, and DIM

\begin{tabular}{lcc}
\hline Item & \multicolumn{1}{c}{ Primiparous } & Multiparous \\
\hline RFI, $\mathrm{kg}$ & $0.00 \pm 1.30(-7.31,5.47)$ & $0.01 \pm 1.79(-13.81,17.96)$ \\
$\mathrm{DMI}, \mathrm{kg} / \mathrm{d}$ & $20.63 \pm 3.23(9.16,32.68)$ & $25.23 \pm 4.47(11.07,44.72)$ \\
$\mathrm{MBW}, \mathrm{kg}$ & $114.6 \pm 8.34(61.6,155.3)$ & $129.5 \pm 10.01(94.22,170.1)$ \\
MilkE, Mcal/d & $24.82 \pm 4.54(6.18,39.45)$ & $32.14 \pm 5.83(10.06,52.74)$ \\
$\mathrm{MY}, \mathrm{kg} / \mathrm{d}$ & $35.38 \pm 6.74(8.34,56.51)$ & $46.35 \pm 8.72(13.73,77.66)$ \\
Fat, \% & $3.69 \pm 0.50(1.85,5.59)$ & $3.66 \pm 0.57(1.83,6.45)$ \\
Protein, \% & $3.00 \pm 0.28(2.28,4.11)$ & $2.96 \pm 0.32(2.01,4.70)$ \\
$\Delta \mathrm{BW}, \mathrm{kg} / \mathrm{d}$ & $0.40 \pm 0.47(-5.21,3.19)$ & $0.29 \pm 0.66(-5.30,4.83)$ \\
DIM & $85.01 \pm 28.67(61,186)$ & $89.28 \pm 30.38(63,185)$ \\
\hline
\end{tabular}


Table 3. Estimates (SE) of phenotypic $\left(\mathrm{r}_{\mathrm{P}}\right)$ and genetic $\left(\mathrm{r}_{\mathrm{g}}\right)$ correlation, additive genetic variance $\left(\sigma_{a}^{2}\right)$, and heritability for residual feed intake (RFI), DMI, metabolic BW (MBW), and milk energy (MilkE) for primiparous and multiparous cows

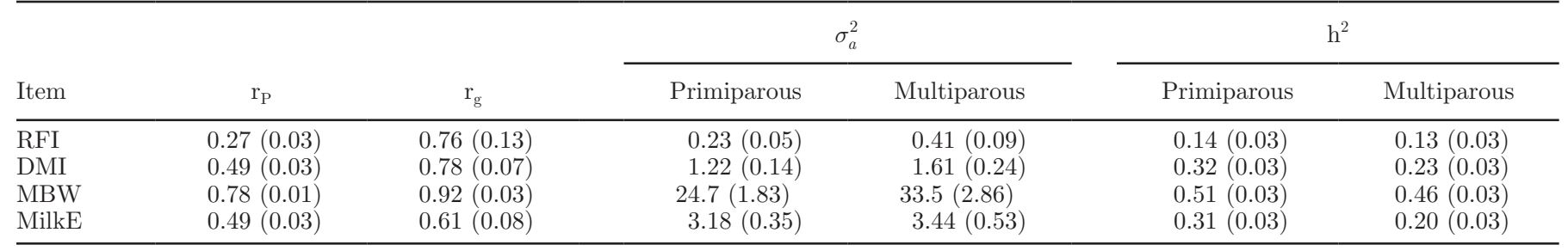

Table 4. Location, percentage of total genetic variance explained, and rank of the ten 1-Mb windows that explained the most genetic variation in primiparous cows for each trait: DMI, residual feed intake (RFI), milk energy (MilkE), and metabolic BW (MBW $)^{1}$

\begin{tabular}{|c|c|c|c|c|c|c|}
\hline Chromosome & $\mathrm{Mb}^{2}$ & Percentage $^{3}$ & $\mathrm{RFI}^{4}$ & DMI & MilkE & MBW \\
\hline 1 & 52 & 0.69 & 3 & & & \\
\hline 2 & 33 & 0.31 & 7 & & & \\
\hline 3 & 102 & 0.55 & & & & 9 \\
\hline 3 & 103 & 0.82 & & & & 5 \\
\hline 4 & 7 & 0.58 & & 10 & & \\
\hline 4 & 14 & 1.35 & & & & $2^{*}$ \\
\hline 5 & 105 & 2.03 & & & & $1^{*}$ \\
\hline 5 & 117 & 0.28 & 9 & & & \\
\hline 5 & 118 & 0.63 & & 7 & & \\
\hline 6 & 88 & $1.15,0.79$ & & & 1 & $6^{*}$ \\
\hline 7 & 18 & 0.49 & & & 9 & \\
\hline 7 & 91 & 0.84 & & & & 4 \\
\hline 8 & 76 & 0.52 & & & 8 & \\
\hline 9 & 84 & 0.46 & & & 10 & \\
\hline 10 & 33 & 1.87 & & $2^{*}$ & & \\
\hline 11 & 76 & 0.79 & 2 & & & \\
\hline 12 & 1 & 1.09 & 1 & & & \\
\hline 12 & 20 & 0.58 & & 8 & & \\
\hline 12 & 25 & 0.60 & 5 & & & \\
\hline 13 & 69 & 0.57 & & & & 8 \\
\hline 17 & 30 & 0.72 & & 5 & & \\
\hline 18 & 5 & 0.55 & & & 5 & \\
\hline 18 & 23 & 1.15 & & & & $3^{*}$ \\
\hline 18 & 64 & 0.28 & 8 & & & \\
\hline 18 & 65 & 0.80 & & 4 & & \\
\hline 19 & 38 & 0.47 & & 9 & & \\
\hline 21 & 2 & 0.59 & & & 4 & \\
\hline 21 & 12 & 0.53 & & & 7 & \\
\hline 22 & 1 & 0.53 & & & & 10 \\
\hline 22 & 37 & 0.60 & & & 3 & \\
\hline 23 & 3 & 1.39 & & & 6 & \\
\hline 23 & 39 & 0.27 & 10 & & & \\
\hline 23 & 47 & 0.68 & & 6 & & \\
\hline 25 & 30 & 0.96 & & $3^{*}$ & & \\
\hline 26 & 32 & 1.89 & & $1^{*}$ & & \\
\hline 27 & 32 & 0.63 & 4 & & & \\
\hline 27 & 33 & 0.44 & 6 & & & \\
\hline 28 & 15 & 0.84 & & & 2 & \\
\hline $\mathrm{X}$ & 132 & 0.68 & & & & 7 \\
\hline
\end{tabular}

${ }^{1}$ Results are based on Bayes B analysis with $1 \%$ of SNP included in the model and starting parameters based on Bayes $\mathrm{C}$ with all SNP included in the model.

${ }^{2}$ Distance in megabases to the start of the window.

${ }^{3}$ Percentage of the total genetic variance explained by the window. $\mathrm{x}, \mathrm{x}$ reflects the traits in the order of the columns from left to right.

${ }^{4}$ Rank is based on the total genetic variance explained by the window, with rank $=1$ denoting the window explaining the greatest percentage of total genetic variance explained for that trait.

*Significance threshold, set at the variance was greater than expected $(0.037 \%)$ for more than $80 \%$ of iterations, was met. 
the current study, resulting in very different estimates of genetic variance for primiparous and multiparous cows. Using the majority of the same cows, but pedigree relationships and a different modeling strategy, Lu et al. (2017) also generated numerically larger estimates of genetic variance for multiparous cows. However, unlike the present study, estimates of residual variance in multiparous cows were nearly 3 times those in primiparous cows, leading to a much greater heritability estimate in primiparous cows (0.39) than in multiparous cows
(0.22). Additionally, the genetic correlation between RFI in primiparous and multiparous cows was less than 1 (Table 3), further supporting that the underlying genetic variation differs in part between primiparous versus multiparous cows.

\section{GWAS for RFI}

The GWAS demonstrated that even though the regulation of RFI includes a genetic component, this

Table 5. Location, percentage of total genetic variance explained, and rank of the ten 1-Mb windows that explained the most genetic variation in multiparous cows for each trait: DMI, residual feed intake (RFI), milk energy (MilkE), and metabolic BW (MBW) ${ }^{1}$

\begin{tabular}{|c|c|c|c|c|c|c|}
\hline Chromosome & $\mathrm{Mb}^{2}$ & Percentage $^{3}$ & $\mathrm{RFI}^{4}$ & DMI & MilkE & MBW \\
\hline 2 & 44 & 0.41 & & 7 & & \\
\hline 2 & 53 & 0.95 & & & & 5 \\
\hline 3 & 114 & 0.38 & & 9 & & \\
\hline 4 & 93 & 0.67 & 2 & & & \\
\hline 4 & 95 & $0.48,0.55$ & 4 & 5 & & \\
\hline 5 & 67 & 0.64 & & 4 & & \\
\hline 6 & 60 & 1.23 & & 1 & & \\
\hline 7 & 18 & 0.39 & & & 6 & \\
\hline 7 & 27 & 0.29 & & 8 & & \\
\hline 7 & 92 & 0.82 & & & & 7 \\
\hline 7 & 93 & 0.83 & & & & 6 \\
\hline 9 & 95 & 0.51 & & & 7 & \\
\hline 11 & 51 & 0.37 & 7 & & & \\
\hline 11 & 13 & 0.35 & & & 10 & \\
\hline 11 & 66 & 0.73 & & 2 & & \\
\hline 11 & 105 & 0.37 & & 6 & & \\
\hline 13 & 43 & 0.34 & 8 & & & \\
\hline 13 & 46 & 0.66 & & & 1 & \\
\hline 14 & 11 & 0.68 & & & & 9 \\
\hline 14 & 20 & 1.24 & & & & $2^{*}$ \\
\hline 18 & 23 & 0.66 & & & & 10 \\
\hline 18 & 57 & 1.08 & & & & $4^{*}$ \\
\hline 19 & 51 & 0.32 & 9 & & & \\
\hline 20 & 27 & 0.39 & & & 4 & \\
\hline 20 & 48 & 0.86 & & & 3 & \\
\hline 21 & 16 & 0.44 & 6 & & & \\
\hline 21 & 25 & 0.31 & 10 & & & \\
\hline 21 & 63 & 0.73 & & & & 8 \\
\hline 22 & 1 & 1.19 & & & & $3^{*}$ \\
\hline 24 & 54 & 0.64 & & 3 & & \\
\hline 25 & 13 & 0.67 & 3 & & & \\
\hline 26 & 28 & 0.47 & 5 & & & \\
\hline 26 & 39 & 0.47 & & & 8 & \\
\hline 26 & 45 & 0.46 & & & 2 & \\
\hline 28 & 20 & 1.62 & & & & $1^{*}$ \\
\hline 28 & 24 & 0.43 & & & 9 & \\
\hline 28 & 26 & 0.30 & & 9 & & \\
\hline 28 & 33 & 0.80 & 1 & & & \\
\hline $\mathrm{X}^{5}$ & 30 & 0.56 & & & 5 & \\
\hline
\end{tabular}

${ }^{1}$ Results are based on Bayes B analysis with $1 \%$ of SNP included in the model and starting parameters based on Bayes $\mathrm{C}$ with all SNP included in the model

${ }^{2}$ Distance in megabases to the start of the window.

${ }^{3}$ Percentage of the total genetic variance explained by the window. $\mathrm{x}, \mathrm{x}$ reflects the traits in the order of the columns from left to right.

${ }^{4}$ Rank is based on the total genetic variance explained by the window with rank $=1$ denoting the window explaining the greatest percentage of total genetic variance explained for that trait.

${ }^{5} \mathrm{X}$ refers to the $\mathrm{X}$-specific portion of the $\mathrm{X}$ chromosome.

* Significance threshold, set at the variance was greater than expected $(0.037 \%)$ for more than $80 \%$ of iterations, was met. 
Table 6. Percentage of genetic variance explained and the corresponding percentage of iterations in which the variance was greater than expected for windows extended beyond $1 \mathrm{Mb}$

\begin{tabular}{llcccc}
\hline Parity $^{1}$ & Trait $^{2}$ & BTA & Position, $^{3} \mathrm{Mb}$ & Percent $^{4}$ & Iteration, $\%$ \\
\hline 1 & MBW & 3 & $102-103$ & 1.05 & 78.6 \\
& RFI & 27 & $31-38$ & 2.13 & $95.3^{*}$ \\
2 & MBW & 7 & $92-93$ & 1.59 & $92.2^{*}$ \\
& RFI & 4 & $93-96$ & 1.50 & 79.5 \\
\hline
\end{tabular}

${ }^{1} 1=$ primiparous cows; $2=$ multiparous cows.

${ }^{2} \mathrm{MBW}=$ metabolic $\mathrm{BW} ; \mathrm{RFI}=$ residual feed intake.

${ }^{3}$ Location in megabases of the window.

${ }^{4}$ Percentage of the total genetic variance explained by the window.

*Significance threshold, set at the variance was greater than expected $(0.037 \%$ multiplied by the number of combined $1-\mathrm{Mb}$ windows) for more than $80 \%$ of iterations, was met.

regulation is highly polygenic with no individual region, explaining a large proportion of the total genetic variation. All GWAS converged; in primiparous cows the $1-\mathrm{Mb}$ window with the greatest TGVM was located at $1 \mathrm{Mb}$ on BTA 12 (Table 4), whereas in multiparous cows the window with the greatest TGVM was found at $33 \mathrm{Mb}$ on BTA 28 (Table 5). No single window was considered statistically significant for either primiparous or multiparous cows (Supplemental Tables S1 and S2; https://doi.org/10.3168/jds.2017-12604). However, in primiparous cows, multiple windows in the region of 31 through $38 \mathrm{Mb}$ on BTA 27 were identified as regions of interest, whereas multiple windows in the region of 93 to $96 \mathrm{Mb}$ on BTA 4 were regions of interest for multiparous cows. Therefore, adjacent windows in these regions were combined into extended windows to determine if they explained a greater than expected proportion of the TGVM. Together, the extended windows on BTA 27 explained $2.13 \%$ of the TGVM, and $95.3 \%$ of these iterations had a greater TGVM than expected for the region (Table 6). Thus, a significant QTL for
RFI in primiparous cows resides in the region of 31 to $38 \mathrm{Mb}$ on BTA 27 (Supplemental Figure S1; https:// doi.org/10.3168/jds.2017-12604). In multiparous cows, the extended region on chromosome 4 explained $1.5 \%$ of TGVM and $79.5 \%$ of the iterations explained greater than the expected proportion of TGVM.

The significant QTL on BTA 27 has previously been associated with variation in DMI in primiparous cows (Veerkamp et al., 2012) and harbors multiple genes (Table 7). Among the genes in this region, the gene that encodes the $\beta-3$ adrenergic receptor (ADRB3), beginning at $32.9 \mathrm{Mb}$, is particularly intriguing as a candidate gene for RFI because of the important role for $\beta$-adrenergic receptors in the mobilization and utilization of energy. In particular, agonists of the $\beta$-adrenergic receptors have long been recognized as repartitioning agents that promote growth efficiency in meat animals (Etherton and Smith, 1991), although their role in lactating animals remains largely undefined. The identification of a significant QTL for RFI that includes the $A D R B 3$ gene, combined with evidence

Table 7. Candidate protein-coding genes in windows extended beyond $1 \mathrm{Mb}$

\begin{tabular}{|c|c|c|c|c|}
\hline Parity $^{1}$ & Trait $^{2}$ & BTA & Position, $\mathrm{Mb}$ & Candidate gene \\
\hline 1 & RFI & 27 & $31-38^{*}$ & $\begin{array}{l}\text { ADAM2, ADAM9, ADAM18, ADAM32, ADGRA2, ADRB3, AP3M2, ASH2L, BAG4, } \\
\text { BRF2, C8Orf4, CHRNA6, CHRNB3, CSGALNACT1, DDHD2, DKK4, EIF } 4 E B P 1, \\
\text { ERLIN2, FGFR1, FNTA, GINS4, GOLGA7, GOT1L1, GPAT4, HGSNAT, HOOK3, } \\
\text { HTRA4, IDO1, IDO2, INTS10, IKBK, KAT6A, KCNU1, LETM2, LSM1, PLAT, } \\
\text { PLEKHA2, PLP5, POMK, PROSC, PSD3, RAB11FIP11, RNF170, SFRP1, SH2D4A, } \\
\text { SLC20A2, SMIM19, STAR, TACC1, THAP1, TM2D2, UNC5D, WHSC1L1, ZMAT4, } \\
\text { ZNF703 }\end{array}$ \\
\hline \multirow[t]{2}{*}{2} & MBW & 7 & $92-93^{*}$ & ADGRV1, ARRDC3, CETN3, LYSMD3, MBLAC2, POLR3G \\
\hline & RFI & 4 & $93-96$ & $\begin{array}{l}\text { AHCYL2, CALU, CCDC136, CEP41, COPG2, CPA1, CPA4, CPA5, FAM71F1, FLNC, } \\
\text { IMPDH1, IRF5, KCP, KLHDC10, LEP, LRRC4, MEST, MKLN1, NRF1, OPN1SW, } \\
\text { PLXNA4, PODXL, PRRT4, RBM28, SMO, SND1, SSMEM1, STRIP2, TMTM209, } \\
\text { TNPO3, TSGA13, TSPAN33, UBE2H, ZC1HC1 }\end{array}$ \\
\hline
\end{tabular}

\footnotetext{
${ }^{1} 1=$ primiparous cows; $2=$ multiparous cows.
}

${ }^{2} \mathrm{MBW}=$ metabolic BW; RFI $=$ residual feed intake.

*Significance threshold, set at the variance was greater than expected (number of combined $\mathrm{Mb} \times 0.037 \%$ ) for more than $80 \%$ of iterations, was met. 
that this gene is expressed in bovine adipose (Sumner and McNamara, 2007) and mammary (Inderwies et al., 2003) tissues, identify $A D R B 3$ as a novel positional candidate gene for future investigation of physiological pathways underlying genetic differences for RFI in lactating Holstein cows.

The extended window on BTA 4 fell just short of reaching the significance threshold used in the present study. Nevertheless, among the genes harbored within this region of BTA 4 is the gene that encodes the hormone leptin ( $L E P)$, starting at 93.2 Mb. Leptin is produced in adipose tissue, proportionally to mass, and functions in part to maintain energy balance by regulating appetite (Henry et al., 1999; Barb et al., 2006). Leptin signals through the central nervous system to elicit changes in feeding behavior, metabolism, and endocrine physiology (Frühbeck et al., 1998) and also stimulates lipolysis through autocrine or paracrine effects on adipocytes (Frühbeck et al., 1997, 1998; Siegrist-Kaiser et al., 1997). Expression of this gene has previously been associated with variation in RFI in dairy cattle (Xi et al., 2015). Comparing mRNA levels in serum samples of cows with low versus high RFI, Xi et al. (2015) found that $L E P$, and other genes in leptinneuropeptide Y signaling pathway, were downregulated in low-RFI cows, suggesting that this pathway may affect feed efficiency. In the current study, the 1-Mb window on BTA 4 beginning at $95 \mathrm{Mb}$ was also identified as a region of interest for DMI in multiparous cows, whereas variants in $L E P$ have previously been associated with variation in feed intake and energy balance albeit in primiparous dairy cattle (Liefers et al., 2002, 2005; Banos et al., 2008).

Prior studies that identified QTL for RFI were primarily focused on RFI in growing dairy cattle or beef steers, other studies focused on relatively small popula-

Table 8. Locations in the bovine genome identified in previous genome-wide association studies as associated with residual feed intake (RFI) in beef or dairy cattle

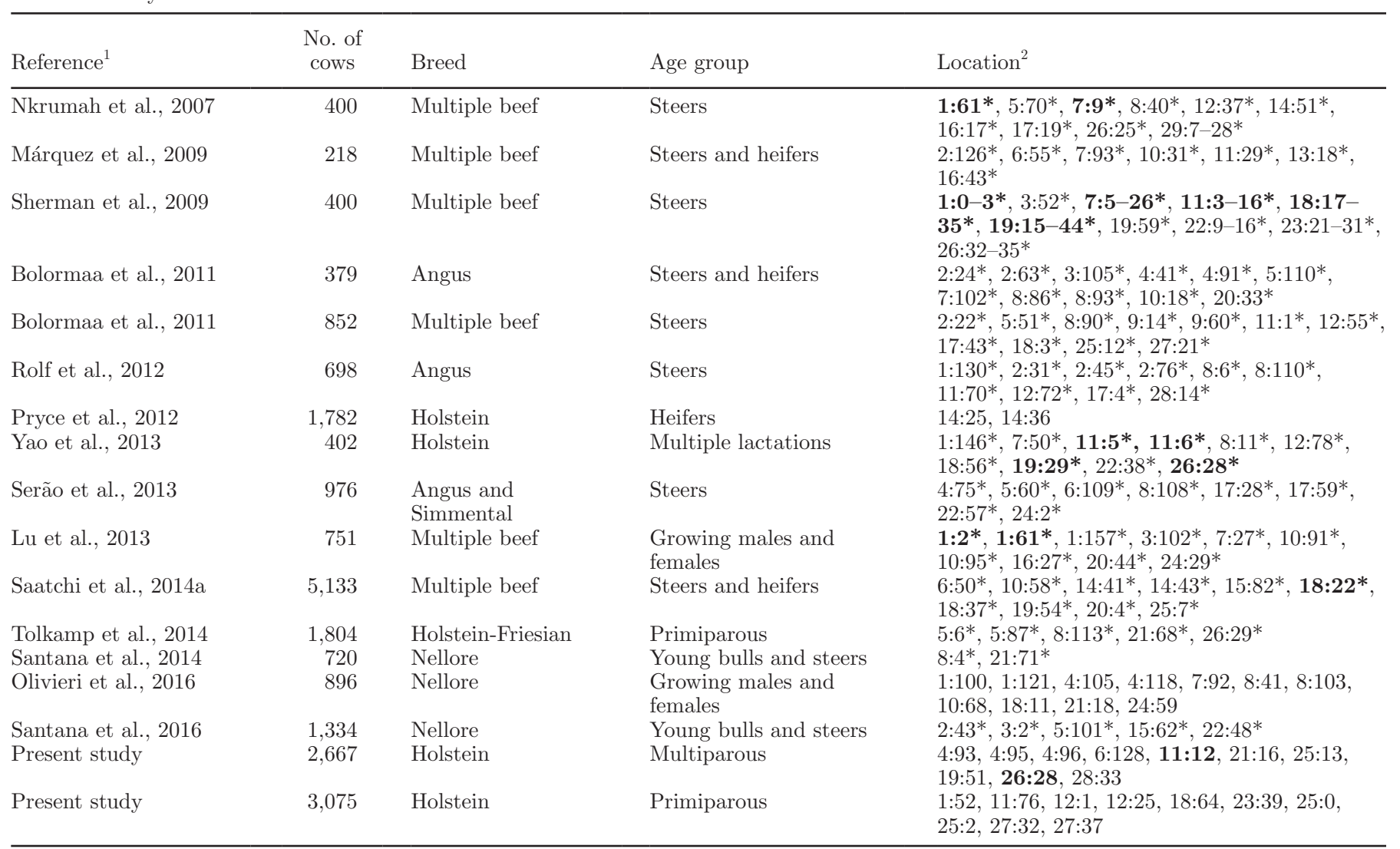

${ }^{1}$ The trait considered in Tolkamp et al. (2014) was energy balance.

${ }^{2}$ The 10 most significant locations or, in the absence of significance criteria, locations explaining the greatest proportion of genetic variance are provided. Format is chromosome:megabase, where the megabases may be a range $(\mathrm{x}-\mathrm{x})$ encompassing a confidence window. Results reported in centimorgans were converted to megabases using an alignment to Baylor cattle SNP provided by AnimalQTLdb (www.animalgenome.org/ QTLdb/; Hu et al., 2016). Locations published as SNP were converted to the whole megabase lying upstream of the SNP using the NCBI SNP database (https://www.ncbi.nlm.nih.gov/snp). Regions in bold are in common between 2 or more studies.

* Significance threshold set in the original study was met. 
tions of lactating mature cows (Table 8). An earlier analysis using novel methodology and a subset of data used in the current study identified 188 SNP associated with RFI (Yao et al., 2013). Only 1 region of the 10 most significant regions reported by Yao et al. (2013) and the current study were in common. However, Yao et al. (2013) and the current study each identified a region on BTA 11 that fell within the same confidence interval identified in beef cattle (Sherman et al., 2009). Many of the significant or most explanatory regions were unique across studies. This observation further supports the conclusion of the current study that RFI is a highly polygenic trait, and may suggest that the identification of QTL influencing RFI is highly sensitive to specific populations, statistical approaches, and definition of RFI studied.

Using data from 527 primiparous cows, Verbyla et al. (2010) predicted that there are 472 QTL for energy balance, which is mathematically equivalent to RFI (Veerkamp, 1998). With only 527 phenotypes, power was not high enough to be able to detect significant
QTL, but Verbyla et al. (2010) suggested that with more phenotypes GWAS could lead to identification of possible candidate genes related to energy balance. As such, we used 4,916 cows in the present study; however, the improvements in power were limited by dividing the records into primiparous and multiparous groups and the lower heritability estimated in the current study than in Verbyla et al. (2010).

\section{GWAS for Underlying Traits}

Similar to RFI, convergence was achieved and only a small proportion of genetic variance was explained by any single $1-\mathrm{Mb}$ window for DMI, MilkE, or MBW in primiparous (Figure 1) or multiparous (Figure 2) cows. In primiparous cows, we noted 7 significant windows across the 4 traits, including 3 windows for DMI (BTA 10, 25, and 26) and 4 windows for MBW (BTA 4, 5, 6, and 18). The region surrounding $105 \mathrm{Mb}$ on BTA 5 has previously been identified as a QTL for body size traits in beef cattle (Saatchi et al., 2014b), and the window

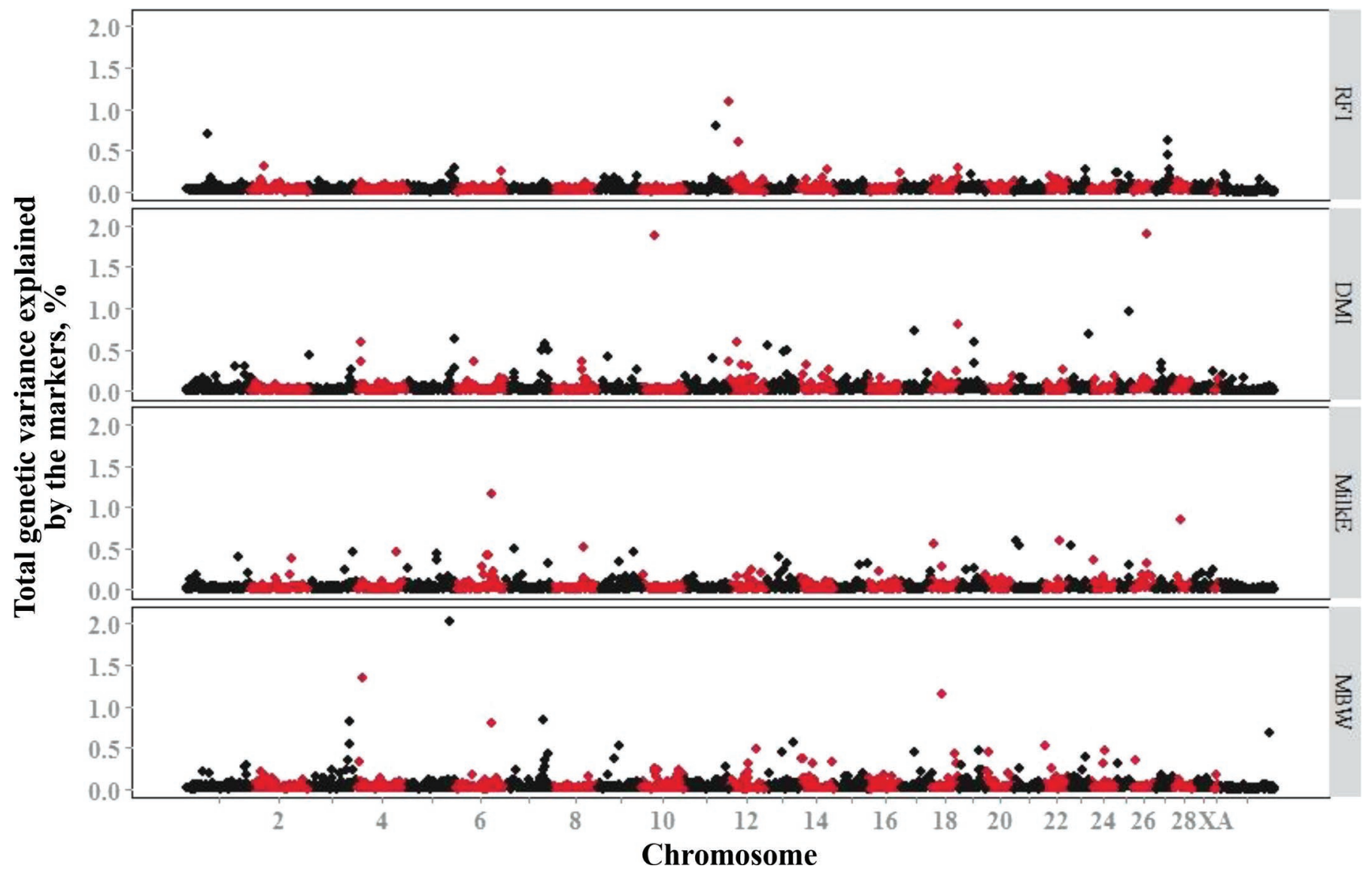

Figure 1. Manhattan plots of 1-Mb windows for residual feed intake (RFI), DMI, and the energy sinks milk energy (MilkE) and metabolic BW (MBW) in primiparous cows. Chromosomal location XA refers to the pseudo autosomal portion of the X chromosome with the X-specific markers, the set of black markers at the right edge of the plots. Color version available online. 
on BTA 6 was also a region of interest for MilkE in primiparous cows.

In multiparous cows, 4 windows (BTA 14, 18, 22, and 28 ) were considered significant and all were associated with MBW (Table 5). The gene-rich region on BTA 18 (Table 9) was previously identified in the US dairy cattle population as related to body size traits. A SNP in this window, ss86324977, had the greatest probability of a nonzero effect on MBW in the present study and was previously identified as explaining the most variation for body depth, sire and daughter calving ease, sire and daughter stillbirth, rump width, stature, and strength (Cole et al., 2009). Cole et al. (2009) identified this SNP as located in an intron of the sialic acid binding IG-like lectin-5 (Siglec) gene, which has been shown to be linked to a leptin deficiency that may cause a delay in parturition and, consequently, larger calf size. The region identified on BTA 14 has been associated with BW traits in beef cattle (Saatchi et al., 2014b), and the region on BTA 28, has been identified as a QTL for birth weight in Angus cattle (McClure et al., 2010).
In addition to the significant QTL defined by the $1-\mathrm{Mb}$ windows, extended windows were investigated for 2 additional regions associated with MBW. In primiparous cows, windows beginning at 102 and 103 $\mathrm{Mb}$ on BTA 3 were combined. This extended window explained $1.05 \%$ of TGVM and $78.6 \%$ of iterations explained greater variance than expected. For multiparous cows, the 1-Mb windows on BTA 7 from 92 to $93 \mathrm{Mb}$ were combined. This extended window explained $1.59 \%$ of TGVM and $92.2 \%$ of iterations explained greater variance than expected. Although only the extended region on BTA 7 achieved statistical significance as defined for the present study, both regions have previously been associated with BW traits in cattle. The extended region on BTA 3 was previously identified as a QTL for body size-related traits, including calf size and calving ease in Charolais cattle (Purfield et al., 2015). Likewise, the extended region on BTA 7 was identified in previous studies in beef cattle for body size-related traits. This region has been significantly associated with birth weight, weaning weight, yearling

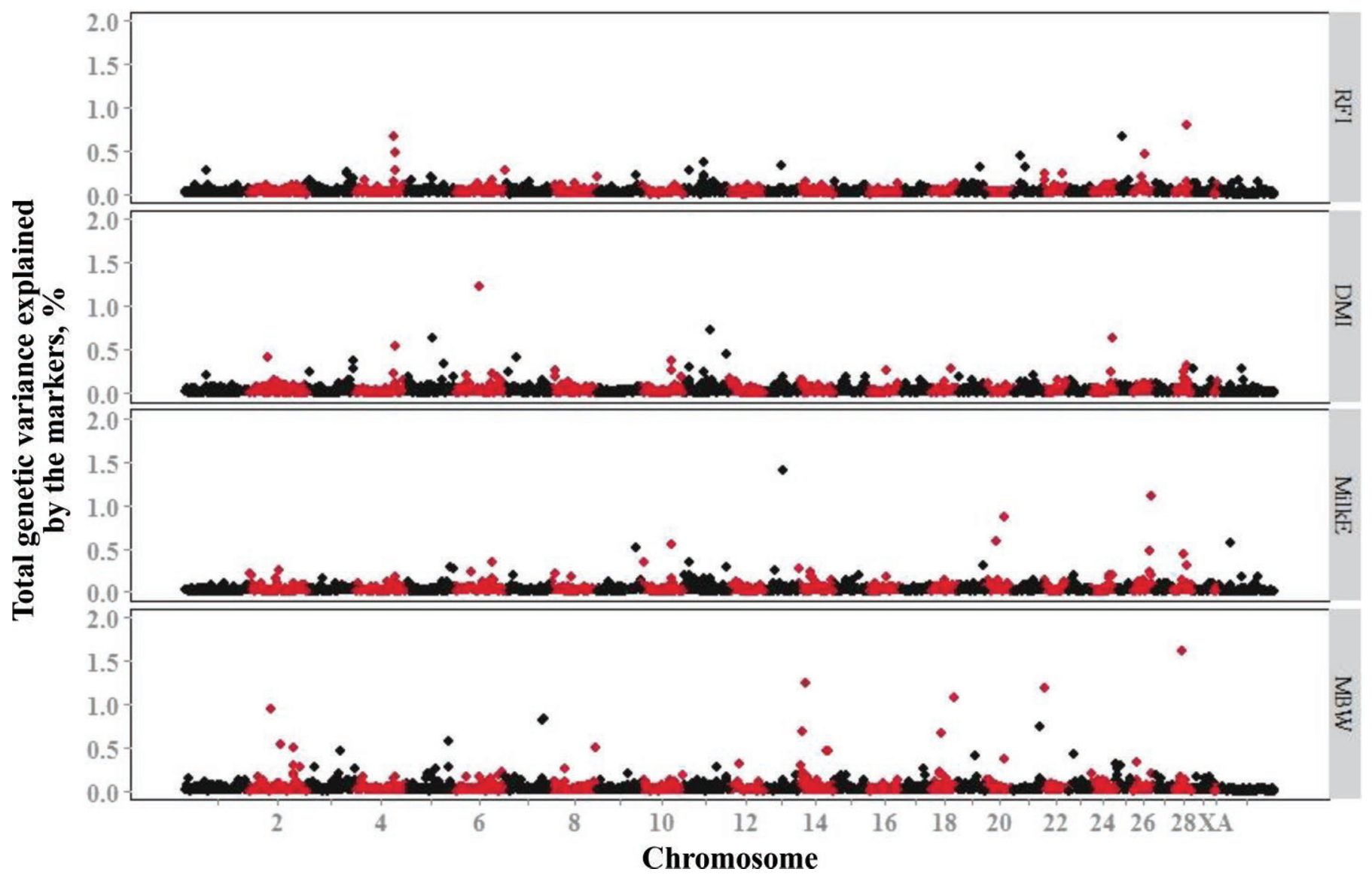

Figure 2. Manhattan plots of 1-Mb windows for residual feed intake (RFI), DMI, and the energy sinks milk energy (MilkE) and metabolic BW (MBW) in multiparous cows. Chromosomal location XA refers to the pseudo autosomal portion of the X chromosome with the X-specific markers, the set of black markers at the right edge of the plots. Color version available online. 
weight, mature weight, and rib eye area across multiple breeds of beef cattle (Snelling et al., 2010; Saatchi et al., 2014b; Weng et al., 2016).

\section{Pleiotropic or Closely Linked Regions}

Overlapping or nearby windows of interest for multiple traits were explored because of the possibility of a pleiotropic QTL causing genetic variation in multiple traits. Regions in common between DMI and RFI but not between DMI with MilkE or MBW were of particular interest because of the possibility that genetic variation here could be exploited to reduce DMI without adversely affecting MilkE or MBW. Three such regions were identified on BTA 12 and 18 in primiparous cows and on BTA 4 in multiparous cows. Additional regions that may characterize pleiotropic effects on multiple traits include the window on BTA 6 , which was a region of interest for MilkE and MBW in primiparous cows; BTA 13 from 43 to $46 \mathrm{Mb}$, which was a region of inter-

Table 9. Candidate protein-coding genes within $2 \mathrm{Mb}$ of significant 1-Mb windows for traits underlying feed efficiency

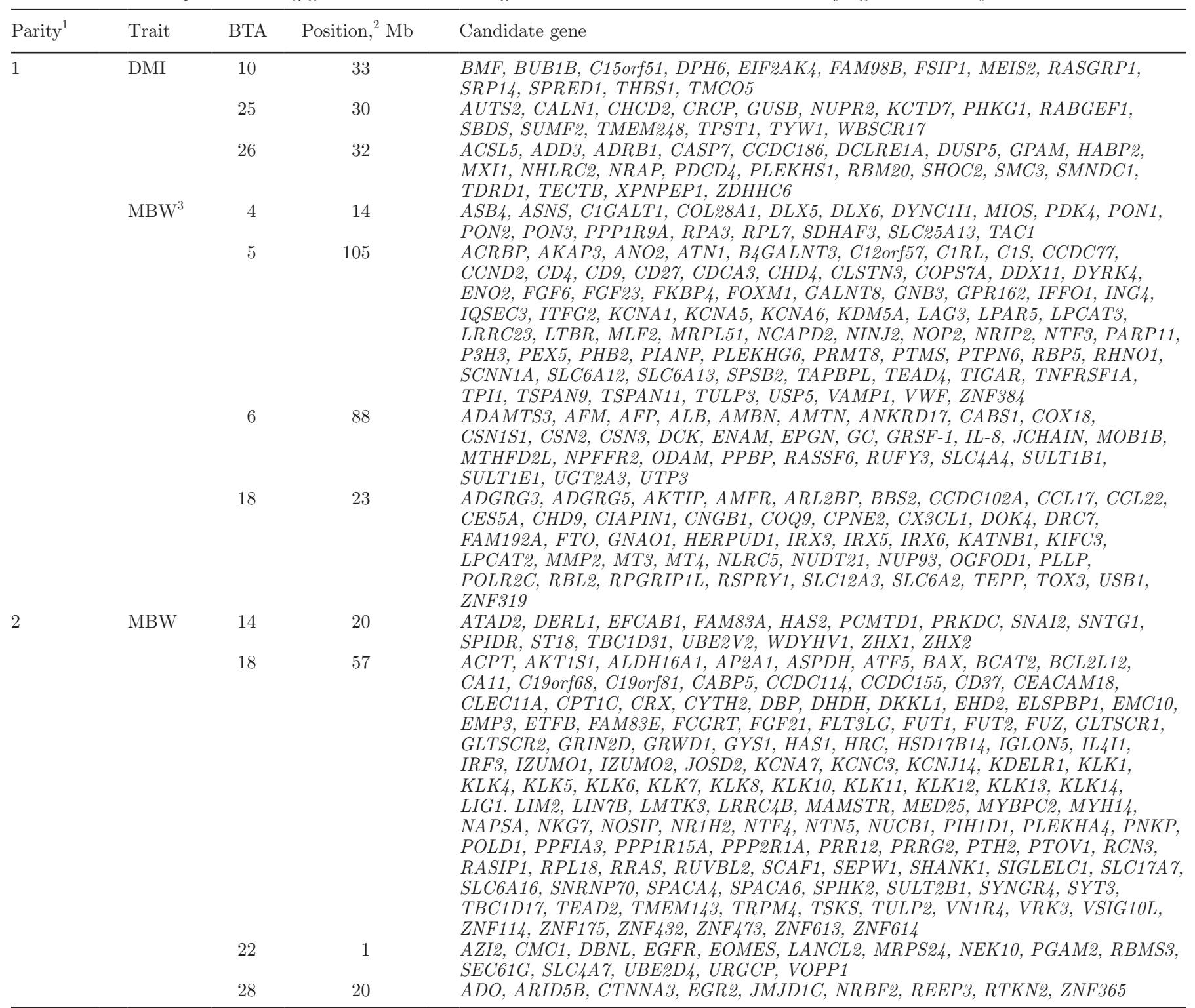

${ }^{1} 1=$ primiparous cows; $2=$ multiparous cows.

${ }^{2}$ Significance declared when, in greater than $80 \%$ of iterations, the variance was greater than expected $(0.037 \%)$.

${ }^{3} \mathrm{MBW}=$ metabolic BW. 
est for MilkE and RFI in multiparous cows; and BTA 28 from 20 to 33, which included regions of interest for all traits evaluated in multiparous cows.

Pleiotropy is not surprising in light of the genetic correlations between these traits. Using nearly 2,000 US cows and more than 2,000 cows from the Netherlands, up to half of which were common with the current study, genetic correlations of 0.70 (the Netherlands) and 0.89 (United States) were estimated between RFI and DMI (Manzanilla-Pech et al., 2016). In both the US and Dutch population of cows, genetic correlations were estimated at 0.63 between DMI and MilkE and at 0.56 in the Netherlands and 0.46 in the US populations between DMI and MBW.

\section{CONCLUSIONS}

This study characterized aspects of the genetic regulation of RFI and related traits of DMI, milk energy and MBW. In general, these traits are highly polygenic with no individual region explaining large proportions of the total genetic variation. Furthermore, the genetic basis of these traits is not static throughout the life of the dairy cow, as indicated by moderate genetic correlations between primiparous and multiparous cows. Nevertheless, 2 noteworthy QTL were identified; in primiparous cows, a significant QTL was identified for RFI on BTA 27 that harbors the positional candidate gene $A D R B 3$, and the region of BTA 4 that harbors the gene encoding $L E P$ was identified as a region of interest for RFI and DMI in multiparous cows. Overall, these results illustrate the physiological complexity underlying the genetic regulation of feed efficiency in lactating dairy cattle.

\section{ACKNOWLEDGMENTS}

This project received financial support from the USDA National Needs Graduate Fellowship Competitive Grant no. 2013-38420-20496 (Washington, DC) and the Agriculture and Food Research Initiative Competitive Grant no. 2011-68004-30340 (Washington, DC).

\section{REFERENCES}

Banos, G., J. A. Woolliams, B. W. Woodward, A. B. Forbes, and M. P. Coffey. 2008. Impact of single nucleotide polymorphisms in leptin, leptin receptor, growth hormone receptor, and diacylglycerol acyltransferase (DGAT1) gene loci on milk production, feed, and body energy traits of UK dairy cows. J. Dairy Sci. 91:3190-3200. https://doi.org/10.3168/jds.2007-0930.

Barb, C. R., R. R. Kraeling, G. B. Rampacek, and G. J. Hausman. 2006. The role of neuropeptide $\mathrm{Y}$ and interaction with leptin in regulating feed intake and luteinizing hormone and growth hormone secretion in the pig. Reproduction 131:1127-1135. https:// doi.org/10.1530/rep.1.01108.
Berry, D. P., M. P. Coffey, J. E. Pryce, Y. de Haas, P. Løvendahl, N. Krattenmacher, J. J. Crowley, A. Wang, D. Spurlock, K. Weigel, K. Macdonald, and R. F. Veerkamp. 2014. International genetic evaluations for feed intake in dairy cattle through the collation of data from multiple sources. J. Dairy Sci. 97:3894-3905.

Boddicker, N., E. H. Waide, R. R. R. Rowland, J. K. Lunney, D. J. Garrick, J. M. Reecy, and J. C. M. Dekkers. 2012. Evidence for a major QTL associated with host response to porcine reproductive and respiratory syndrome virus challenge. J. Anim. Sci. 90:17331746. https://doi.org/10.2527/jas.2011-4464.

Bolormaa, S., B. J. Hayes, K. Savin, R. Hawken, W. Barendse, P. F. Arthur, R. M. Herd, and M. E. Goddard. 2011. Genome-wide association studies for feed lot and growth traits in cattle. J. Anim. Sci. 89:1684-1697.

Cole, J. B., P. M. VanRaden, J. R. O'Connell, C. P. Van Tassell, T. S. Sonstegard, R. D. Schnabel, J. F. Taylor, and G. R. Wiggans. 2009. Distribution and location of genetic effects for dairy traits. J. Dairy Sci. 92:2931-2946. https://doi.org/10.3168/jds.2008-1762.

de Haas, Y., J. E. Pryce, M. P. L. Calus, E. Wall, D. P. Berry, P. Løvendahl, N. Krattenmacher, F. Miglior, K. Weigel, D. Spurlock, K. A. Macdonald, B. Hulsegge, and R. F. Veerkamp. 2015. Genomic prediction of dry matter intake in dairy cattle from an international data set consisting of research herds in Europe, North America, and Australasia. J. Dairy Sci. 98:6522-6534. https://doi .org/10.3168/jds.2014-9257.

Etherton, T. D., and S. B. Smith. 1991. Somatotropin and $\beta$ _adrenergic agonists: Their efficacy and mechanisms of action. J. Anim. Sci. 69(Suppl.2):2-26.

Fernando, R.L., and D.J. Garrick. 2009. GenSel-User manual for a portfolio of genomic selection related analyses. 3rd ed. Iowa State University. Accessed Jan. 12, 2017. https://www.biomedcentral .com/content/supplementary/1471-2105-12-186-s1.pdf.

Fernando, R. L., and D. J. Garrick. 2013. Bayesian methods applied to GWAS. Pages 237-274 in Methods in Molecular Biology. Humana Press, New York City, NY.

Frühbeck, G., M. Aguado, and J. A. Martínez. 1997. In vitro lipolytic effect of leptin on mouse adipocytes: Evidence for a possible autocrine/paracrine role of leptin. Biochem. Biophys. Res. Commun. 240:590-594. https://doi.org/10.1006/bbrc.1997.7716.

Frühbeck, G., S. A. Jebb, and A. M. Prentice. 1998. Leptin: Physiology and pathophysiology. Clin. Physiol. 18:399-419. https://doi .org/10.1046/j.1365-2281.1998.00129.x.

Garrick, D. J., and R. L. Fernando. R. L. 2013. Implementing a QTL detection study (GWAS) using genomic prediction methodology. Pages 275-298 in Methods in Molecular Biology. Humana Press, New York City, NY.

Gilmour, A. R., B. J. Gogel, R. B. Cullis, S. J. Welham, and R. Thompson. 2015. ASReml User Guide. Release 4.1. Accessed Jan. 12 2017. http://www.vsni.co.uk/downloads/asreml/release4/ UserGuideStructural.pdf.

Habier, D., R. L. Fernando, K. Kizilkaya, and D. J. Garrick. 2011. Extension of the Bayesian alphabet for genomic selection. BMC Bioinformatics 12:186. https://doi.org/10.1186/1471-2105-12-186.

Henry, B. A., J. W. Goding, W. S. Alexander, A. J. Tilbrook, B. J. Canny, F. Dunshea, A. Rao, A. Mansell, and I. J. Clarke. 1999. Central administration of leptin to ovariectomized ewes inhibits food intake without affecting the secretion of hormones from the pituitary gland: Evidence for a dissociation of effects on appetite and neuroendocrine function. Endocrinology 140:1175-1182. https://doi.org/10.1210/endo.140.3.6604.

Hu, Z. L., C. A. Park, and J. M. Reecy. 2016. Developmental progress and current status of the Animal QTLdb. Nucleic Acids Res. 44:D827-D833. https://doi.org/10.1093/nar/gkv1233.

Inderwies, T., M. W. Pfaffl, H. H. D. Meyer, J. W. Blum, and R. M. Bruckmaier. 2003. Detection and quantification of mRNA expression of alpha- and beta-adrenergic receptor subtypes in the mammary gland of dairy cows. Domest. Anim. Endocrinol. 24:123-135.

Knapp, J. R., G. L. Laur, P. A. Vadas, W. P. Weiss, and J. M. Tricarico. 2014. Invited review: Enteric methane in dairy cattle production: Quantifying the opportunities and impact of reducing 
emissions. J. Dairy Sci. 97:3231-3261. https://doi.org/10.3168/jds .2013-7234

Koch, R. M., L. A. Swiger, D. Chambers, and K. E. Gregory. 1963. Efficiency of feed use in beef cattle. J. Anim. Sci. 22:486-494.

Liefers, S. C., M. F. te Pas, R. F. Veerkamp, and T. van der Lende. 2002. Associations between leptin gene polymorphisms and production, live weight, energy balance, feed intake, and fertility in Holstein heifers. J. Dairy Sci. 85:1633-1638.

Liefers, S. C., R. F. Veerkamp, M. F. te Pas, C. Delavaud, Y. Chilliard, M. Platje, and T. van der Lende. 2005. Leptin promoter mutations affect leptin levels and performance traits in dairy cows. Anim. Genet. 36:111-118.

Lu, D., S. Miller, M. Sargolzaei, M. Kelly, G. V. Voort, T. Caldwell, Z. Wang, G. Plastow, and S. Moore. 2013. Genome-wide association analyses for growth and feed efficiency traits in beef cattle. J. Anim. Sci. 91:3612-3633.

Lu, Y., M. J. VandeHaar, D. M. Spurlock, K. A. Weigel, L. E. Armentano, C. R. Staples, E. E. Connor, Z. Wang, M. Coffey, R. F. Veerkamp, Y. de Haas, and R. J. Tempelman. 2017. Modeling genetic and nongenetic variation of feed efficiency and its partial relationships between component traits as a function of management and environmental factors. J. Dairy Sci. 100:412-427. https://doi .org/10.3168/jds.2016-11491.

Manzanilla-Pech, C. I. V., R. F. Veerkamp, R. J. Tempelman, M. L. van Pelt, K. A. Weigel, M. VandeHaar, T. J. Lawlor, D. M. Spurlock, L. E. Armentano, C. R. Staples, M. Hanigan, and Y. De Haas. 2016. Genetic parameters between feed-intake-related traits and conformation in 2 separate dairy populations - the Netherlands and United States. J. Dairy Sci. 99:443-457. https://doi.org/ 10.3168/jds.2015-9727.

Márquez, G. C., R. M. Enns, M. D. Grosz, L. J. Alexander, and M. D. MacNeil. 2009. Quantitative trait loci with effects on feed efficiency traits in Hereford $\mathrm{x}$ composite double backcross populations. Anim. Genet. 40:986-988.

McClure, M. C., N. S. Morsci, R. D. Schnabel, J. W. Kim, P. Yao, M. M. Rolf, S. D. McKay, S. J. Gregg, R. H. Chapple, S. L. Northcutt, and J. F. Taylor. 2010. A genome scan for quantitative trait loci influencing carcass, post-natal growth and reproductive traits in commercial Angus cattle. Anim. Genet. 41:597-607. https://doi .org/10.1111/j.1365-2052.2010.02063.x.

NRC. 2001. Nutrient Requirements of Dairy Cattle. 7th rev. ed. Natl. Acad. Press, Washington, DC.

Nkrumah, J. D., E. L. Sherman, C. Li, E. Marques, D. H. Crews Jr., R. Bartusiak, B. Murdoch, Z. Wang, J. A. Basarab, and S. S. Moore. 2007. Primary genome scan to identify putative quantitative trait loci for feedlot growth rate, feed intake, and feed efficiency of beef cattle. J. Anim. Sci. 85:3170-3181.

Olivieri, B. F., M. E. Z. Mercandante, J. N. D. S. G. Cyrillo, R. H. Branco, S. F. M. Bonilha, L. G. de Albuquerque, R. M. de Oliveira Silva, and F. Baldi. 2016. Genomic regions associated with feed efficeiency indicator traits in an experimental Nellore cattle population. PLoS One 12:e0171845. https://doi.org/10.1371/journal .pone.0164390.

Perotto, D., R. I. Cue, and A. J. Lee. 1992. Comparison of nonlinear functions for describing the growth curve of three genotypes of dairy cattle. Can. J. Anim. Sci. 72:773-782.

Pryce, J. E., J. Arias, P. J. Bowman, S. R. Davis, K. A. Macdonald, G. C. Waghorn, W. J. Wales, Y. J. Williams, R. J. Spelman, and B. J. Hayes. 2012. Accuracy of genomic predictions of residual feed intake and 250-day body weight in growing heifers using 625,000 single nucleotide polymorphism markers. J. Dairy Sci. 95:2108 2119. https://doi.org/10.3168/jds.2011-4628.

Purfield, D. C., D. G. Bradley, R. D. Evans, F. J. Kearney, and D. P. Berry. 2015. Genome-wide association study for calving performance using high-density genotypes in dairy and beef cattle. Genet. Sel. Evol. 47:47. https://doi.org/10.1186/s12711-015-0126-4.

Rolf, M. M., J. F. Taylor, R. D. Schnabel, S. D. McKay, M. C. McClure, S. L. Northcutt, M. S. Kerley, and R. L. Weaber. 2012. Genome-wide association analysis of feed efficiency in Angus cattle. Anim. Genet. 43:367-374.
Saatchi, M., J. E. Beever, J. E. Decker, D. B. Faulkner, H. C. Freetly, S. L. Hansen, H. Yampara-Iquise, K. A. Johnson, S. D. Kachman, M. S. Kerley, J. Kim, D. D. Loy, E. Marques, H. L. Neibergs, E. J. Pollak, R. D. Schnabel, C. M. Seabury, D. W. Shike, W. M. Snelling, M. L. Spangler, T. L. Weaber, D. J. Garrick, and J. F. Taylor. 2014a. QTLs associated with dry matter intake, metabolic midtest weight, growth and feed efficiency have little overlap across 4 beef cattle studies. BMC Genomics 15:1004.

Saatchi, M., R. D. Schnabel, J. F. Taylor, and D. J. Garrick. 2014b. Large-effect pleiotropic or closely linked QTL segregate within and across ten US cattle breeds. BMC Genomics 15:442. https://doi .org/10.1186/1471-2164-15-442.

Santana, M. H. A., M. C. Freua, D. N. Do, R. V. Ventura, H. N Kadarmideen, and J. B. S. Ferraz. 2016. Systems genetics and genome-wide association approaches for analysis of feed intake, feed efficiency, and performance in beef cattle. Genet. Mol. Res. 15:gmr15048930. https://doi.org/10.4238/gmr15048930.

Santana, M. H. A., Y. T. Utsunomiya, H. H. R. Neves, R. C. Gomes, J. F. Garcia, H. Fukumasu, S. L. Silva, G. A. Oliveira Junior., P. A. Alexandre, P. R. Leme, R. A. Brassaloti, L. L. Coutinho, T. G. Lopes, F. V. Meirelles, J. P. Eler, and J. B. S. Ferraz. 2014. Genome-wide association analysis of feed intake and residual feed intake in Nellore cattle. BMC Genet. 15:21.

Serão, N. V. L., D. González-Peña, J. E. Beever, D. B. Faulkner, and B. R. Southey. 2013. Single nucleotide polymorphisms and haplotypes associated with feed efficiency in beef. BMC Genet. 14:94. https://doi.org/10.1186/1471-2156-14-94.

Sherman, E. L., J. D. Nkrumah, C. Li, R. Bartusiak, B. Murdoch, and S. S. Moore. 2009. Fine mapping quantitative trait loci for feed intake and feed efficiency in beef cattle. J. Anim. Sci. 87:37-45.

Siegrist-Kaiser, C. A., V. Pauli, C. E. Juge-Aubry, O. Boss, A. Pernin, W. W. Chin, I. Cusin, F. Rohner-Jeanrenaud, A. G. Burger, J. Zapf, and C. A. Meier. 1997. Direct effects of leptin on brown and white adipose tissue. J. Clin. Invest. 100:2858-2864. https://doi .org/10.1172/JCI119834.

Snelling, W. M., M. F. Allan, J. W. Keele, L. A. Kuehn, T. McDaneld, T. P. L. Smith, T. S. Sonstegard, R. M. Thallman, and G. L. Bennett. 2010. Genome-wide association study of growth in crossbred beef cattle. J. Anim. Sci. 88:837-848. https://doi.org/10.2527/jas .2009-2257.

Spurlock, D., and M. VandeHaar. 2013. Regulation of feed efficiency in dairy cattle. CAB Rev. 8:039. https://doi.org/10.1079/ PAVSNNR20138039.

Sumner, J. M., and J. P. McNamara. 2007. Expression of lipolytic genes in the adipose tissue of pregnant and lactating Holstein dairy cattle. J. Dairy Sci. 90:5237-5246. https://doi.org/10.3168/ jds.2007-0307.

Tempelman, R. J., D. M. Spurlock, M. Coffey, R. F. Veerkamp, L. E. Armentano, K. A. Weigel, Y. de Haas, C. R. Staples, E. E. Connor, Y. Lu, and M. J. VandeHaar. 2015. Heterogeneity in genetic and nongenetic variation and energy sink relationships for residual feed intake across research stations and countries. J. Dairy Sci. 98:2013-2026. https://doi.org/10.3168/jds.2014.8510.

Tolkamp, A., M. P. Coffey, E. Wall, D. P. Berry, E. Strandberg, and R. F. Veerkamp. 2014. Functional cluster analysis of genome wide associations for energy balance for cows in experimental herds in four European countries. In Proceedings 10th World Congr. Genet. Appl. to Livest. Prod. Vancouver, Canada. American Society of Animal Science, Champaign, IL.

USDA-NASS. 2015. 2015 Wisconsin Agricultural Statistics. Wisconsin Field Office 1-64. USDA National Agricultural Statistics Service and Wisconsin Department of Agriculture, Trade and Consumer Protection Wisconsin Field Office, Madison, WI.

VandeHaar, M. J., L. E. Armentano, K. Weigel, D. M. Spurlock, R. J. Tempelman, and R. Veerkamp. 2016. Harnessing the genetics of the modern dairy cow to continue improvements in feed efficiency. J. Dairy Sci. 99:4941-4954.

VandeHaar, M. J., and N. St-Pierre. 2006. Major advances in nutrition: Relevance to the sustainability of the dairy industry. J. Dairy Sci. 89:1280-1291. https://doi.org/10.3168/jds.S0022 -0302(06)72196-8. 
VanRaden, P. M. 2008. Efficient methods to compute genomic predictions. J. Dairy Sci. 91:4414-4423. https://doi.org/10.3168/jds .2007-0980

Veerkamp, R. F. 1998. Selection for economic efficiency of dairy cattle using information on live weight and feed intake: A review. J. Dairy Sci. 81:1109-1119. https://doi.org/10.3168/jds.S0022 -0302(98)75673-5.

Veerkamp, R. F., M. P. Coffey, D. P. Berry, Y. de Haas, E. Strandberg, H. Bovenhuis, M. P. L. Calus, and E. Wall. 2012. Genome-wide associations for feed utilisation complex in primiparous HolsteinFriesian dairy cows from experimental research herds in four European countries. Animal 6:1738-1749.

Verbyla, K. L., M. P. L. Calus, H. A. Mulder, Y. de Haas, and R. F. Veerkamp. 2010. Predicting energy balance for dairy cows using high-density single nucleotide polymorphism information. J. Dairy Sci. 93:2757-2764. https://doi.org/10.3168/jds.2009-2928.

von Keyserlingk, M. A. G., N. P. Martin, E. Kebreab, K. F. Knowlton, R. J. Grant, M. Stephenson, C. J. Sniffen, J. P. Harner III, A. D. Wright, and S. I. Smith. 2013. Invited review: Sustainability of the US dairy industry. J. Dairy Sci. 96:5405-5425. https://doi.org/10 $.3168 /$ jds.2012-6354.

Weng, Z., H. Su, M. Saatchi, J. Lee, M. G. Thomas, J. R. Dunkelberger, and D. J. Garrick. 2016. Genome-wide association study of growth and body composition traits in Brangus beef cattle. Livest. Sci. 183:4-11. https://doi.org/10.1016/j.livsci.2015.11.011.

Wiggans, G. R., T. A. Cooper, D. J. Null, and P. M. VanRaden. 2014. Increasing the number of single nucleotide polymorphisms used in genomic evaluations of dairy cattle. In Proceedings, 10th World Congr. Genet. Appl. to Livest. Prod. Vancouver, Canada. American Society of Animal Science, Champaign, IL.

Wolc, A., J. Arango, P. Settar, J. E. Fulton, N. P. O'Sullivan, R. Preisinger, D. Habier, R. Fernando, D. J. Garrick, W. G. Hill, and J. C. M. Dekkers. 2012. Genome-wide association analysis and genetic architecture of egg weight and egg uniformity in layer chickens. Anim. Genet. 43(Suppl. 1):87-96. https://doi.org/10.1111/j.1365 $-2052.2012 .02381 . x$.

Xi, Y. M., Z. Yang, F. Wu, Z. Y. Han, and G. L. Wang. 2015. Gene expression profiling of hormonal regulation related to the residual feed intake of Holstein cattle. Biochem. Biophys. Res. Commun. 465:19-25. https://doi.org/10.1016/j.bbrc.2015.07.092.

Yao, C., D. M. Spurlock, L. E. Armentano, C. D. Page Jr., M. J. VandeHaar, D. M. Bickhart, and K. A. Weigel. 2013. Random Forests approach for identifying additive and epistatic single nucleotide polymorphisms associated with residual feed intake in dairy cattle. J. Dairy Sci. 96:6716-6729. https://doi.org/10.3168/jds.2012-6237. 